\title{
Youth First: A Canadian Youth-led Initiative in the Midst of the COVID-19 Pandemic
}

\author{
Reah (Hyun Ju) Shin, Harleen Kaur, Catherine Howe, Justin Whitty, Kyla Quigley, Regan \\ Katerenchuk, Victoria Bonnell, Ronglan Cao, Geoffrey Pearson and James Liu
}

\author{
M.A. Students \\ Graduate Program in Child and Youth Care \\ Faculty of Community Services \\ Ryerson University
}

\begin{abstract}
This reflection writing was co-written by seven young people between the ages of 19 and 24 who are located in various places in Canada such as British Columbia, Ottawa and Ontario. They have been part of the Youth First's Online Youth Advisory Group in partnership with three Master of Arts Child and Youth Care (MA CYC) students from Ryerson University. Our writing centres around a Canadian youth-led initiative called Youth First, initially created as a CYC student initiative that became a MA CYC placement due to the lack of placement opportunities available during the pandemic. Youth First focused on creating safe and interactive spaces in cyberspace for young people during the pandemic. Through this reflection, we hope to share our experiences, accomplishments, lessons learned, and overall reflection of being part of this initiative during a global pandemic.
\end{abstract}

Keywords: youth-led initiatives, children's rights, participation, cyberspace, COVID-19 
Figure 1. A Youth First art initiative submission ${ }^{1}$

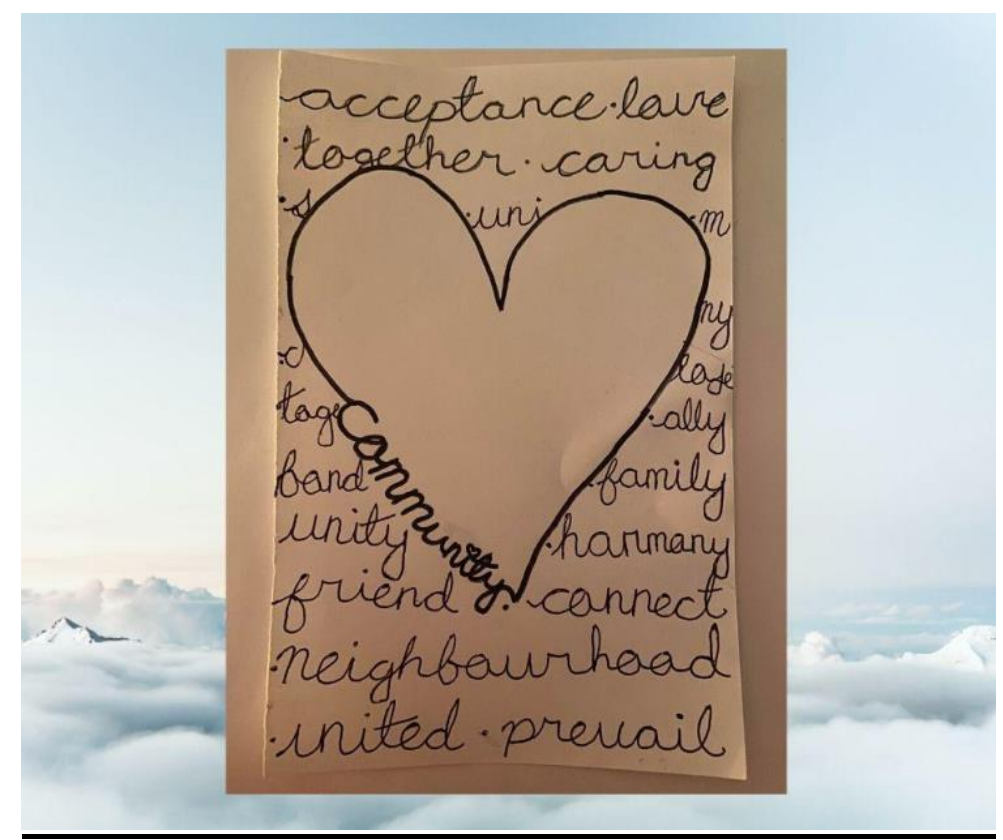

"I enjoyed feeling useful for the first time since the pandemic hit, and I feel as though I met some very interesting people through this program." G.P., OYAG member

Youth First is a project that was led by a group of Master of Arts Child and Youth Care (MA CYC) students (Reah Shin, Catherine Howe and Kyla Quigley) and young people from the Youth First's Online Youth Advisory Group (OYAG) (Harleen Kaur, Justin Whitty, Regan Katerenchuk, Victoria Bonnell, Ronglan Cao, Geoffrey Pearson and James Liu). The members of the OYAG were recruited by the MA CYC students to engage in meaningful initiatives to support young people during the pandemic. Youth First included various initiatives that were led by the OYAG members with the support from the MA CYC students. Though Youth First originally began as an initiative created by the Ryerson's MA CYC program (Master of Arts of Child and Youth Care) for students with an anticipated outcome of co-creating a youth-led environment while connecting and supporting young people during the initial stages of the pandemic. After the initiative was created, the project became one of Ryerson MA CYC's placement opportunities that replaced other virtual or in-person placements that were being delayed due to the pandemic. The initiative began in March 2020 and came to an end in late August 2020. When the MA CYC students began to strategize the general, fluid and flexible structure of the initiative, the MA CYC students decided to create specific OYAGs that aligned with their professional background. As such, there was an OYAG focusing on shelter-related initiatives including seven young people and two CYC students; another OYAG focused on disabilities-related initiatives including six young people and two CYC students. Outside of the core three CYC students who worked with the OYAG members to co-create and facilitate the meetings and initiative, there were nine CYC 
students who supported outreach, social media and promotion of Youth First. The director of the MA CYC program provided ongoing advice and support.

This initiative was originally inspired by the virtual MA CYC meetings with the MA CYC faculty members and students discussing the personal, professional and societal impacts of the pandemic in relation to $\mathrm{CYC}$ practice and education. There were discussions on the dedication of CYC practitioners to support young people regardless of the pandemic creating additional barriers to access CYC services. From these conversations, MA CYC student Reah Shin, hoped to respond to the current events happening in the world as well as to have an opportunity to work alongside and learn from young people who wished to support other young people who had been affected by the pandemic. Reah then shared the idea of starting a virtual initiative to bring their idea into action to the MA CYC Program Director Judy Finlay. Reah then proposed it to the rest of the MA CYC students and faculty. The first members of Youth First included the three MA CYC students: Kyla Quigley, Catherine Howe and Reah Shin. The MA CYC students agreed that starting a youth-led initiative to support young people would be a meaningful way to be active in their communities. Noting the importance of authentic youth participation, the MA CYC students acknowledged that the Youth First's work could not begin until young people were part of the initiative. Therefore, OYAG was created for the young people to advise, lead, co-facilitate and cocreate the direction of the Youth First initiative and be the leaders for the implementation of the initiatives created by the OYAG members. Further discussions on OYAG will be explored later in the paper.

For the MA CYC students, advocating for children's rights articulated in the United Nations Convention on the Rights of the Child (UN CRC) (1989) has been an important dedication in their program and practice. Regardless of the pandemic restricting MA CYC placement opportunities, the students were dedicated to young people's right to participation (Article 12), right to freedom of peaceful assembly (Article 15), and the right to the best interest of the child (Article 3). The UN CRC has been a motivator for the CYC to create this initiative. Many of the steps to building the initiative unfolded organically through the intention to build a caring community, with little experience of how to do so under unprecedented conditions, but with a great passion to meet this objective. The authors hope that this paper can be inspiring for young people, CYC practitioners, educators and other professionals working alongside young people.

As a way of celebrating the end of this initiative and reflecting on the process, some of the OYAG members and the MA CYC students collaborated on writing this article. While we were planning and writing, it was important for us to work together to decide on the different aspects to include in the article such as the order of author names or the number of responsibilities shared on writing. The order of the author names was decided based on the number of contributions made to the final manuscript (noting that the order of the author names does not represent the degree of contributions to the overall initiative). The OYAG members created most of the text and took the lead in describing the initiatives, achievements, lessons learned and the final thoughts. The MA CYC students contributed by describing the creation of Youth First, providing further details on 
the initiative process as well as including the students' personal reflections and lessons learned from this experience.

In total, there were 22 OYAG members who were directly engaged in Youth First. In the final stage, there were 10 OYAG members and three MA CYC students involved in the initiative. Additionally, there were 140 young people and adults who were part of the Youth First Facebook group who shared resources and connected with one another.

\section{How Youth First was Created}

Some of the OYAG members and the MA CYC students had been part of social media groups and communities before starting this initiative. An MA CYC student posted questions on these platforms asking, "as a young person, how are you doing?" and "what would you like to see during this time?"; the number of responses to these questions was overwhelming. There were over 100 young people and families who responded on Facebook and social media platforms, sharing their thoughts and experiences. Through the responses, the MA CYC students noticed a theme emerging that young people were expressing how a lot of their voices and opinions were not being heard and that many felt disconnected from what was happening in the world. Once again, the MA CYC student posted on social media about the idea of collaborating with young people to begin this initiative. In this early stage, the name for the initiative was not created as it was important for the development and planning to be achieved in partnership with young people. This post opened further dialogues with young people who were interested in joining the initiative.

Figure 2. Youth First team dynamic chart².

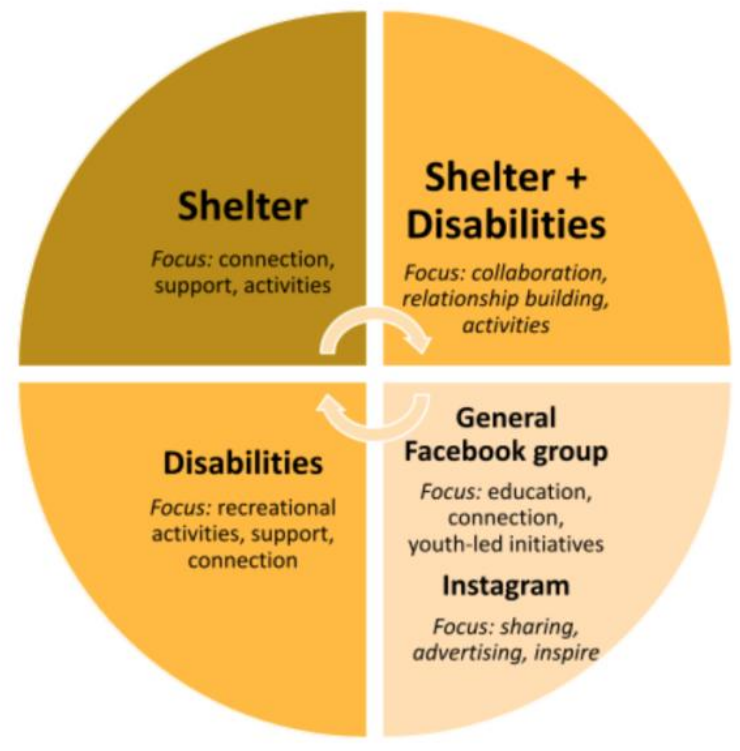

Note: The 13 OYAG members were part of leading the Shelter, Disabilities, and Shelter + Disabilities teams. There was one MA CYC student in the Shelter team and two MA CYC students in the Disabilities team. Three MA CYC students were part of the Youth First social media team. 
These online dialogues with young people were held in an inclusive and open-minded virtual environment where youth from various backgrounds exchanged ideas on how to create meaningful connections during the pandemic. Through these initial conversations, it became clear that young people were being significantly impacted by the unpredictability and significant life changes the pandemic presented. These discussions led to the decision to focus on two main initiatives under Youth First (young people residing in shelters and young people with disabilities), with OYAG and MA CYC students who were directly or indirectly involved in the shelter system or living with disabilities. Three MA CYC students focused on recruiting interested young people and other MA CYC students to join the initiative. The MA CYC students recruited members through social media and connections developed with youth-related organizations, especially the emphasis on youth-created and youth-led organizations. To recruit MA CYC students and OYAG members, the three founding members reached out to faculty members and students to spread the invitation. Through this initial outreach, the two OYAGs (shelter and disabilities) were formed along with the CYC student group.

The exciting partnership between the MA CYC students and the young people began. It was clear that it was a very dynamic team with diverse backgrounds and identities, lived experiences, age, values, and other social locations. It was important for the OYAG members and the MA CYC students to reflect on the imbalance of power that existed in the initiative. Further discussion on how the participants in the initiative discussed how to mitigate and reflect on these power imbalances will be presented below.

When the core MA CYC students and the OYAG members officially began their partnership, there were many discussions on relationship-building as well as how to create a name and a mission statement for Youth First: building a collaborative community with the acknowledgement of our paths and stories. $\mathrm{We}^{3}$ also focused on developing a fluid initial plan for our initiative. Following these initial meetings, each OYAG team began to have separate virtual weekly meetings through video conferencing. We focused on getting to know each other and forming relational connections that became the foundation of our initiative. It was important for us to recognize that all young people carried unique life stories and experiences. We completed background research and had dialogues on the experiences of young people impacted by the pandemic. It was imperative to create a space that reflected kindness, consideration, curiosity, openness, and compassion. In addition, we hoped to create connections, foster empathy, and support others during this unprecedented time. We also formed connections to community organizations such as youth shelters and NGOs. For example, we connected with an Indigenous NGO called Finding Our Power Together (https://findingourpowertogether.com). We invited one of the members from this organization to join one of our weekly OYAG meetings to inform us about the impact of the pandemic on some of the Indigenous young people who the organization was supporting and received tips on the organization's donation process. We realized that one informative session would not be enough to learn about this topic comprehensively, but it provided us with knowledge and resources to continue the conversation in our future meetings. 
Partnership with other organizations and youth-led initiatives proved to be a great way for us to learn and reflect on our initiative.

\section{Youth First Initiatives}

\section{Initiative \#1: Young people with disabilities}

The six young people and the two MA CYC students supporting young people with disabilities wished to create opportunities to connect and participate in artistic and recreational activities together. Online platforms and social media quickly became an important means to support connection and facilitate these activities during the pandemic. One of our OYAG members reflected that isolation and anxiety were heightened in the early stages of the pandemic and that Youth First became an important and supportive outlet to help them cope with these challenges, to have something to look forward to weekly and to feel like they were contributing to something important.

With considerations to creating connectedness and collaboration, we focused on creating opportunities for recreation that might be accessible to a large audience. Together, we brainstormed the idea for an online art-initiative and an Open-Mic event which was held through a video platform online. The art initiative explored weekly themes including hope, strength, connection, community, and together while apart. Young people with disabilities across Canada submitted various artworks of what the themes meant to the young people. The figure below is an example of a submission by a young person shared on Youth First social media platforms, such as Facebook and Instagram.

Figure 3. A Youth First Art initiative submission ${ }^{4}$

As a group we decided a theme of Community. I believe that as youth, we need to have a sense of community to support each other. As citizens we need to believe in each other and work collaboratively to build a bette society. It is better to contribute to a good community and be a global citizen then to only care about ourselves.

As a 23-year-old male I have been diagnosed with Asperger's syndrome. This made my life tough because I had a lot of obstacles to overcome. During my early school years people bullied me and called me stupid and lazy. Obviously, this really made be upset because I felt like an outcast. I had very few friends growing up, although fortunately I did have a couple of close friends that had my back. They were there for me when I needed them most. I also have an older brother who is incredibly supportive and a good role model for me. I am also fortunate to have a loving family with supportive parents. Therefore, I do consider myself fairly lucky although my life really turned around when a teacher in elementary school believed in my potential and at that time hidden talents.

My teacher guided me and gave me perspective about what was really important, and also gave me a sense of hope because he told me that I was very capable. He told me that I was smart and that every student should be treated with respect. He would encourage me to work hard and to never give up no matter what people said about me! At the end of my elementary school time, I was awarded the Principal Award for Leadership. This success encouraged me to fully participate in all school activities, pursuing my interests in sports and music. I was not successful all the time but at least I felt part of the community. 
Through this experience I realized the importance of community for all of us and the importance of supporting others. Folks that were close to me and cared about me, help by giving me hope along with convincing other people to have faith in me as well.

If we want people to be valued and to become valued in the eyes of others, then we must do things which strongly prompt others to perceive them in positively valued ways and they must be perceived by others as holding valued social roles. Everyone has a positive social role to contribute in the community and should be given the opportunity to enjoy the good things in life.

As a newly graduated student in the (DSW) Developmental Service Worker program at Centennial College, I want to help the intellectually disabled to have a supportive community where they can be active community members. I know from personal experience the feeling of being socially isolated and how the sense of belonging can boost a person's sense of wellbeing. This is what inspires me to use a community theme in the Call of Youth Advisory group to help create strong communities throughout the city of Toronto.

By supporting strong communities throughout the city of Toronto we can help build stronger citizens. By supporting stronger citizens, we can build a stronger society! Every citizen deserves to be perceived to have a positive social role within their community. If we can help citizens to be perceived positively by the rest of society then we can build a better world!

\section{J.W.}

Through social media or email, we accepted submissions of different forms of creative expression: poetry, photography, art, painting, word-slam, music. The submissions were then shared on multiple Youth First social media platforms. It was important to maintain an openness to various forms of expression, a value we carried forward into our online Open-Mic Hour.

Figure 4. Promotional posters for Youth First events ${ }^{5}$

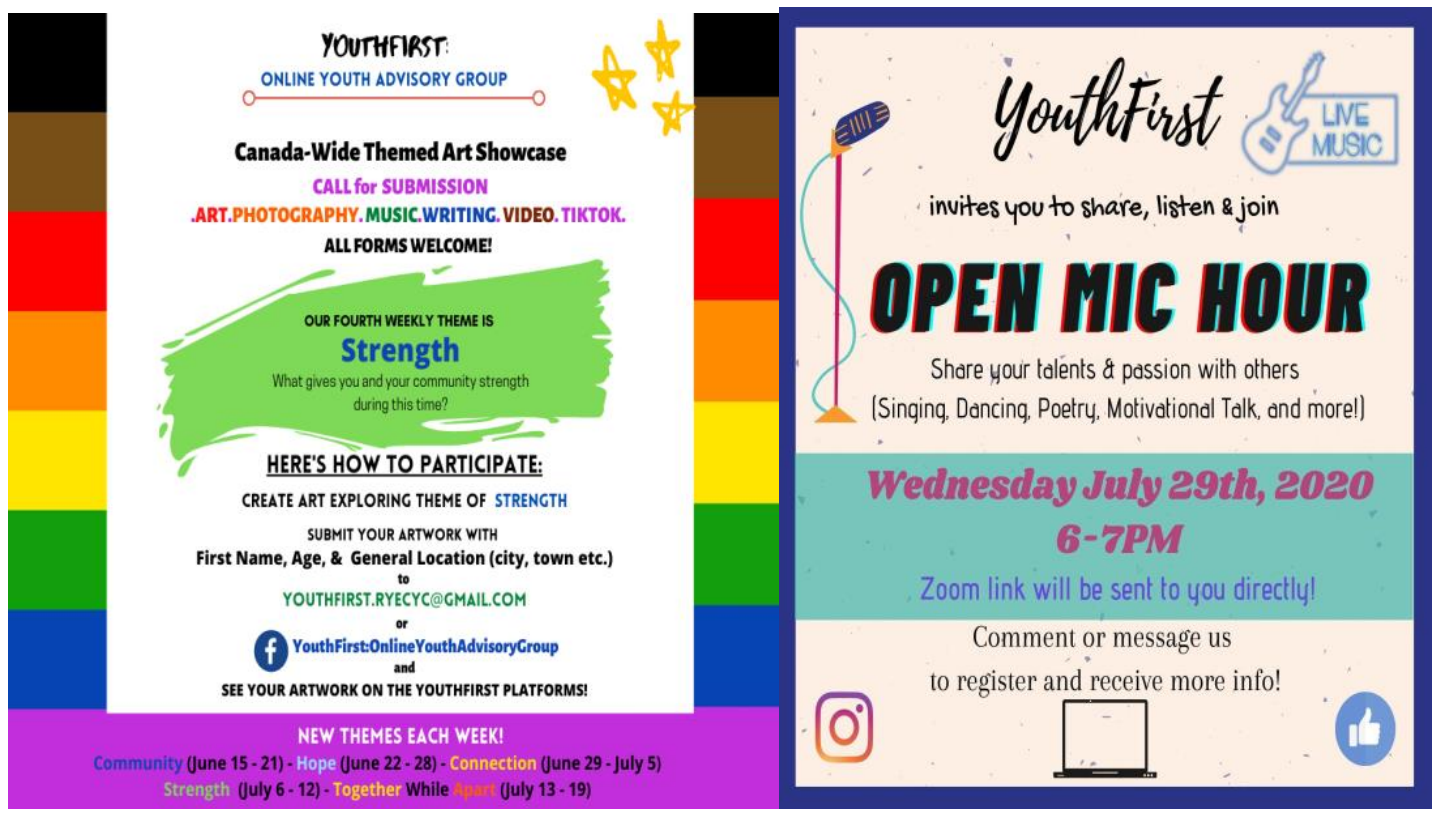


Invitations to participate in the Open-Mic Hour were posted on Youth First social media including weekly themed posters co-created during OYAG meetings. In addition, many of our youth shared the invitation through word of mouth. Both OYAGs joined the open-mic event to host and participate in the event. A success of the Open-Mic Hour was that it provided an outlet for young people to share their talent and practice their passion with other youth in a supportive environment. It was a great learning experience for our whole team and some of the talents shared have left a lasting impression on us. As an OYAG member noted about a community youth's poetry shared during the Open-Mic Hour, "I still think about her poem!"

Although community participation was sometimes low, we learned a lot about outreach and those who participated expressed gratitude for the opportunity to share their talents in a supportive environment. It was a valuable online learning experience, in addition to being fun.

\section{Initiative \#2: Young people residing in shelters}

For this initiative, seven young people and one MA CYC student supporting young people residing in a shelter hoped to provide support to youth in shelters by donating high-need items. We first assessed and examined youth homelessness in Canada to better understand this topic before proceeding with our initiative. All of us brought forward our resources and discussed the lessons learned in our weekly OYAG meetings. Some of our resources included: Summary Report: Youth Homelessness and COVID-19: How the youth serving sector is coping with the crisis (2020), Plan to End Youth Homelessness in Calgary (2011), Without a Home: The National Youth Homelessness Survey (2016), and more. From this research, we were able to identify some of the unique experiences of young people residing in shelters during the time of a pandemic. Other interesting and important topics of discussion for us were young people who were experiencing homelessness but not residing in shelters, young people who were experiencing "invisible" or "hidden" homelessness (Schifalacqua, Ghafoori \& Jacobowitz, 2019), as well as young people who were experiencing homelessness who are living in rural areas.

We researched youth shelters in the different areas that the OYAG members were residing in and chose to support the only youth shelter in Calgary, Avenue 15, through an OYAG member connection. It was important to us that the shelter determined the preferred donation items, rather than us arbitrarily donating what we might assume would be needed. As such, we stayed in communication with the workers at the shelter to decide which items to donate. The young people and workers at the shelter identified high-needs donation items and communicated them with us. The most high-need items consisted of slippers, phone chargers and art supplies. Ongoing collaboration was a core value of our work. As a team, we created a donation letter to express our values and mission and identify the items that we needed to distribute to potential donors. Along with the donation letter, we created a Fact Sheet (Appendix A) outlining the current situations of young people experiencing homelessness in Canada and in Calgary because we valued the importance of others being informed of the realities of Canadian youth homelessness. We started the GoFundMe campaign to fundraise for the shipping cost from Toronto to Calgary in July 2020. 
We researched businesses in our areas to send the donation letter to and did recruitment with our community members as well. It was also important for us to reach out to organizations or companies that worked to respect and protect children's rights. As such, we carefully facilitated in-depth research on the specific companies we were hoping to reach out to.

We reached out to Canada Post and registered Youth First as a small business to receive a discount for shipping. After sending our donation letter and the Fact Sheet, we successfully completed our drive thanks to our donors from community members and IKEA North York that generously donated most of the items on our list. As such, we were able to donate slippers, phone chargers and art supplies for each young person residing at Avenue 15. For us, it was very important for all young people to receive the same number of new items; we were able to achieve this with the support of IKEA and our hard work.

In addition to the donation items to support the young people residing in Avenue 15, we wished to find a way to emotionally connect with the young people in the shelter. Therefore, prior to shipping the donations, both OYAG teams collaborated to create "letters of encouragement" which included letters for each young person in the shelter that were written by all of us in the Youth First team. We then shipped all of our donations along with the letters to Calgary. There was an option for us to ship the donations straight to the shelter, but we thought it would be a lot more meaningful for an OYAG member to hand-deliver the items to the shelter. Therefore, we shipped the items to the house of an OYAG member living in Calgary who then delivered the items to the shelter.

Figure 5. IKEA donations to the Calgary youth shelter, Avenue $15^{5}$

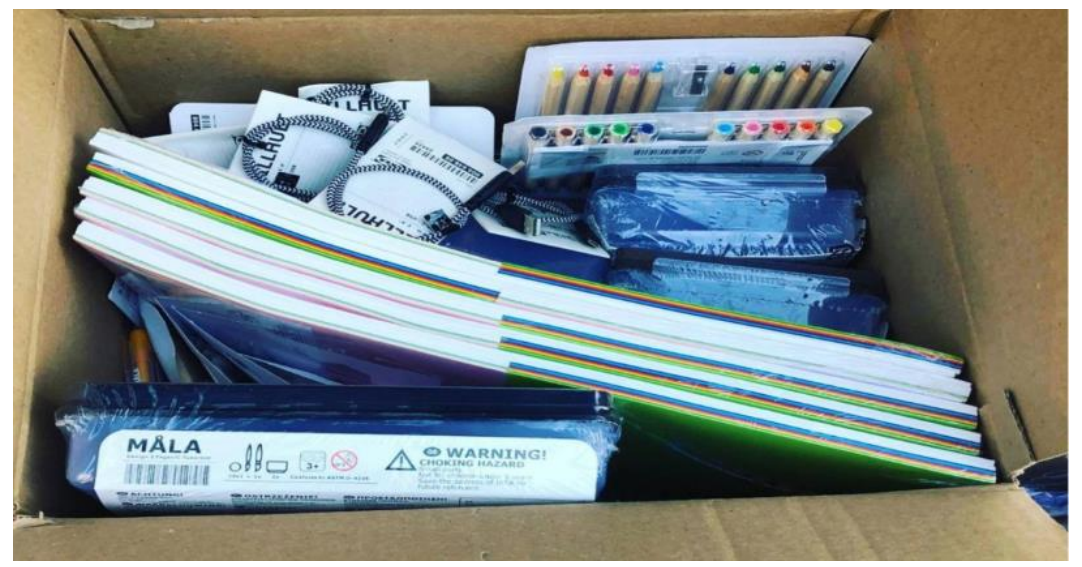




\section{What We Achieved}

Reflecting, learning or un-learning, and challenging one another played significant roles in coming to realize our accomplishments and outcomes. We spread awareness about problems affecting our communities and provided much needed connection between young people, communities and families. We successfully donated important items to young people staying at Avenue 15. We collected and showcased artwork from young people in Canada and hosted the Open-Mic Hour for young people to share their talents in a safe and inclusive setting. In addition, we created opportunities for others to support youth in Canada including community partners, young people, families, friends, and ourselves. People who donated were very kind and we are very grateful for their generosity and support. Our initiative could not have been done without the support of our community members and organizations.

All of us who joined the Youth First team were looking for means of social engagement while schools and other community centres were on lockdown. We cultivated a safe space where we showed respect for each other and our differences, as well as an invitation to join something and be a part of something at a critical time for youth. In our meetings, we spoke of the global pandemic, Black Lives Matter protests, and the spike of Anti-Asian racism since COVID-19. Because all of us came from various racial and cultural backgrounds, we all were impacted directly and indirectly by these social events. We debriefed and provided support to one another during this difficult time. We also reflected on how we can work together to teach, practice, and reflect from an anti-racist and anti-oppressive lens.

A consistent theme throughout our time together was that many people really wanted to connect, share, and contribute to the well-being of others during this difficult time. As such, we learned to use technology in a new and innovative way to foster new connections between people that would never have met otherwise. We realize that there can be harm or privacy issues that can come with online interactions. Moreover, we noticed that news and media outlets often focused on the negative aspects of cyberspace. Therefore, it was amazing that young people reflected the importance this medium held for co-creating a safe space in the online world. Authentic care, understanding, patience and compassion were visible throughout our process. As tragic and challenging adjusting to the pandemic was, we also saw this stressful time bring people together and demonstrate care in ways often overlooked in the bustle of typical everyday life.

\section{What We Learned}

The tough part about the Youth First project was to ensure that anyone who wanted to participate was able to. Nothing was in-person due to the pandemic and everything needed to be done online. Exploring and promoting accessibility in cyberspace was a valuable learning experience. To achieve this, we reviewed resources together to identify what inclusivity in the online space looks like. We had image descriptions for our posts, included our contact information at the bottom of posters for others to provide us with feedback if there were further revisions required to make the posts more accessible, and made sure we were choosing the correct fonts and colours so that everyone could read the posters without issues. This was very interesting for all of 
us and a great learning experience for promoting inclusivity in the online space. We were also mindful of young people who did not have access to the internet and had discussions on how we could be inclusive to everyone and not discriminate due to their access to technology. Though we did not overcome this barrier as we would have liked, we had thoughtful conversations about how we could if the initiative were expanded or through greater community outreach.

Another challenge we faced was that we could not address every social issue through our initiative. We wanted to support young people experiencing homelessness who did not have access to shelters; provide support for young people and families with disabilities or experiencing homelessness; we wished to create more initiatives. However, it was important for us to take a step back and reflect on the realistic framework of support we could provide with respect to our scope and resources. We had to come to a difficult realization that we, unfortunately, could not tackle every single issue and that it would be more meaningful to set realistic goals and approaches.

It was important for the MA CYC students to acknowledge the inherent power imbalance and potential influence on the youth participants in the initiative. As the intention was to privilege the ideas, voices and needs of young people first and foremost, after the first few OYAG meetings the young people took on the role of chairing the meetings; facilitating the entire meeting; notetaking during the meetings; leading icebreakers and closing activities; deciding upon ideas for the initiative (through voting and discussion) and guiding the initiative as a whole. The process became very organic and at times challenged the MA CYC students to reflect upon the potential effects of their influence, to become comfortable being led by the ideas of the young people, and to continually return to a position of amplifying young people's ideas on how to meet community needs. This was a valuable experience for the MA CYC students to embody a strengths-based and relational outlook and to practice what it means to support youth participation.

Attempting recruitment for initiatives or online events but not getting responses from others was an interesting learning curve. We saw some of the attendance go down as the lock down regulations began to be lifted, such as when schools reopened, and people started to go back into their workplaces. However, it was important for us to meet each other where we were at, instead of trying to force any participation relating to our initiative. Another lesson that we learned is that shipping the items to Calgary from Toronto (especially during a pandemic) took longer than usual. Due to the pandemic, it was not easy to get in contact with the necessary postal office and other businesses, as well as to make the delivery. Moreover, it was necessary to be highly cautious and manage risk during COVID-19. This was a new practice for all of us and it put a new strain on interacting with businesses and items. Overall, we gained many skills from being part of Youth First such as creating posters online, branding ourselves, negotiating and reaching out to businesses, writing professional letters and emails, doing outreach to different communities in cyberspace, and more. 


\section{Reflecting On Our Experience}

We all joined Youth First for different reasons and gained numerous takeaways from the experience. Being part of Youth First made us feel involved with the community. We absolutely enjoyed supporting our communities and creating positive changes in the lives of young people, big and small. A lot of us were so eager to help others during this time. Access to youth volunteering opportunities during the pandemic had decreased and we were grateful to be part of Youth First to engage in activities we wished to do. We were happy that we had something meaningful and new to do during quarantine in the safety of our homes.

Each time we met, we had discussions about the Youth First initiatives themselves, but also about the current global events. Not only were the effects of COVID-19 a core topic, we were also engaged in conversations and reflected about social justice, systemic racism and other societal issues. OYAG members and the MA CYC students both brought articles, posters and brochures to our weekly meetings to reflect on these topics. We listened, informed, educated and supported one another.

We also learned about youth participation and what that means for us. We learned that participation looks different for everyone, and all forms of participation are just as important. Some of us participated by speaking during our meetings, contributing in the chat, having conversations in-between meetings, doing outreach to other organizations and young people, and taking on tasks that fit our unique interests. We learned the value of working together for the prosperity of our community. It gave us joy and happiness having the opportunity to support young people in our communities.

We also learned that everyone needs connection in some way and at some point in time. This can look different to everyone., too! We grew and learned together with the power of connection in a virtual space during an unprecedented time not only simply meeting one another, but creating and being part of an ongoing, safe and supportive community in cyberspace that was meaningful to us. A lot of us did not have experience with being part of an online community, so this was new to most of us. There are often many negative situations related to the online space in young people's lives, so it was nice getting to create and be in a safe online space. We felt like we were utilizing technology in a very meaningful and innovative way.

One very meaningful part of participating in this group initiative was getting to know one another. We really enjoyed meeting new people through Youth First. Though we were planning together to help other young people during the pandemic, Youth First and the Online Youth Advisory Members became a support system for one another. We checked in with one another on a regular basis and connected in between our meetings. We got to personally know one another which made us feel supported and safe. This experience made us feel inspired, encouraged, and happy.

Through Youth First, we have learned that it truly does take a village to make an impact on our communities. We began as strangers with a similar goal of supporting young people and over time, became friends who actively collaborated, shared ideas and learned new ways to accomplish our objectives. During this unusual time, we did not know how possible it would be to 
connect and build a caring community but we managed to form a unique way to have everyone's voices heard and ideas come forward so that the initiative could be continuously shaped by all members. It was amazing to see how we could connect with each other through technology.

We did not know how the initiative would be shaped, which was a unique way to work together. This allowed for many voices and ideas to come forward and for the initiative to be continuously shaped and informed by all members. We took risks trying different ways to connect and build community during this unusual time. Not only did we get to know people we would otherwise have never met, we also worked collaboratively and built upon each other's skill sets. We learned that there are many like-minded individuals in the world and were able to share and support young people's unique abilities, artistic interests and creative talents.

The online forum can also foster patience, as things don't always go as planned, communication can be affected by technology, and some things take longer than they might otherwise. With this understanding in mind, it was great to see everyone patiently and mindfully support each other.

\section{Conclusion}

Participating in this initiative offered us a great opportunity to collaborate in supporting young people during the pandemic. What we realized near the end of the initiative was that our Youth First itself was also supporting $u s$. We really looked forward to our meetings each week where we played games, sang songs, discussed personal achievements, talked about our struggles, and got to know one another. Near the end of our initiative, we had many meetings of both OYAGs together as we had all developed relationships throughout the initiative. It was also a great way for us to debrief and reflect about our initiative, and to work on this writing together.

Youth First taught us the value of unity and being part of a global community. It was inspiring to know that there are like-minded individuals out there who are happy to take initiative to make our world a better place. We loved sharing interests and skills through events, such as our Open-Mic Night. We were able to strengthen connections, meet new people and discover the special talents of our team members. We thrived on building an online community during this difficult time and worked together to identify and meet the needs of young people in our broader communities.

We also realized that none of this would have happened without the circumstances of the pandemic. Through this challenging, hurtful, and saddening time, we still found hope and strength together and we created something beautiful out of it. We used the online space, which often is viewed as something that is harmful to young people, to positively connect, relate, and support one another. Overall, it was our relationship that was the foundation and the drive of our whole initiative.

Although the initiatives from Youth First have ended, our social media platforms remain open to the public for young people in Canada to continue this important dialogue and connect with one another. As an OYAG member said, "(we) learned the value of unity and being a part of a global community and changes can be made when a team of like-minded individuals take action." 
To find out more information about Youth First, please join our Youth First Facebook group: https://www.facebook.com/groups/1125388234488851

\section{Acknowledgements}

We would like to thank all of the young people who were part of the Youth First journey including our previous OYAG, social media youth members, as well as our caregivers, families and friends who have been supporting our initiative. Our thanks to IKEA and community members for their donations, Avenue 15 for communicating with us and allowing us to send the donations, as well as Canada Post for providing us with support on shipping. We would also like to thank the director of the MA CYC program, Dr. Judy Finlay for her ongoing advice and support throughout the process, as well as the MA CYC Faculty members and students.

\section{Appendix A: Youth Homelessness in Canada: Fact Sheet}

YOUTH

HOMELESSNESS

IN CANADA:

Fact Sheet

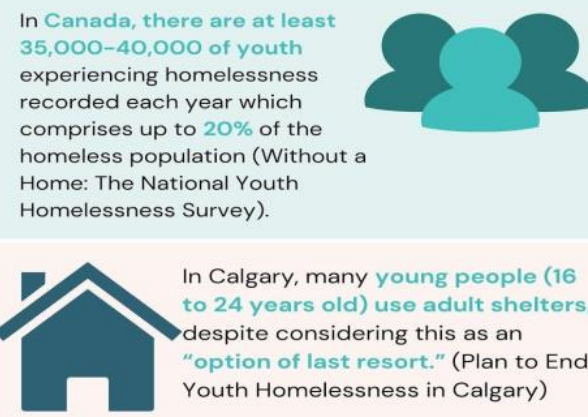

The $20 \%$ estimated percentage of Canada's homeless population are young people aged 13 to 24 . (The State of Homelessness in Canada: 2014)

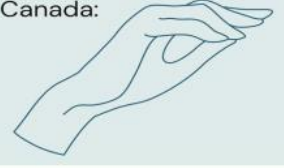

Even youth who do have access to shelters have reported feeling isolated and distressed from the lack of basic necessities.

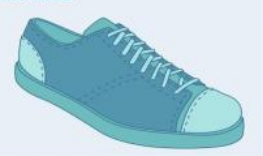

THANK YOU FOR YOUR GENEROUS DONATIONS. TO MAKE DONATIONS, PLEASE CONTACT: YOUTHFIRSTRYECYC@GMAIL.COM

OR CALL/TEXT 2898126938

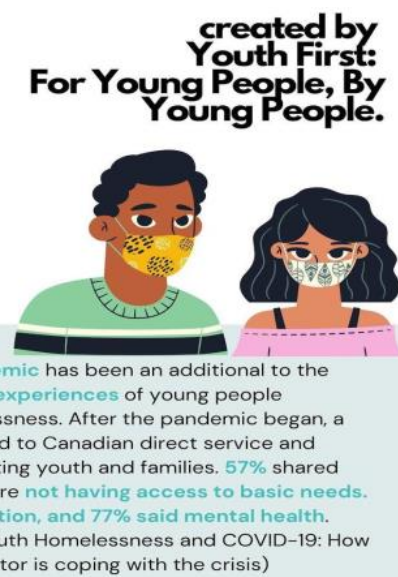

$63.1 \%$ percent of homeless youth identified physical, sexual, or other forms of abuse as contributing to their homelessness. (Without a Home: The National Youth

Homelessness Survey)

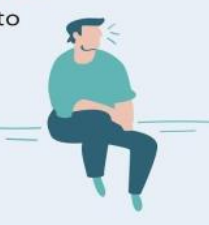

Buchnea, A., McKitterick, M-J.\& \& French, D (2020). Summary Report Youth Homelessness and COVID-19: How the youth Observatory on Homelessness Press and A Way Home Canada.Calgary

Homeless Foundation (2011). Plan to End Youth Homelessness in Calgary.

S. Gaetz, B. O'Grady, S. Kidd, \& Schwan, K. (2016). Without a Home: The National Youth Homelessness Survey. Toronto: Canadian Observatory on Homelessness; A Way Home Canada; Nationa Learning Community on routh Homelessness. te of Homelessne:s Network Press. Tonadian Homelessness Research 


\section{References}

Buchnea, A., McKitterick, M. J., French, D. (2020). Summary report: Youth homelessness and COVID-19: How the youth serving sector is coping with the crisis. Toronto, ON

Calgary Plan to Prevent and End Youth Homelessness (2011). Homelessness Hub. Retrieved February 18, 2021 from https://www.homelesshub.ca/resource/calgarys-10-year-plan-endhomelessness-2008-2018-january-2011-update

Finding Our Power Together (n.d.). Finding Our Power Together. https://findingourpowertogether.com

Schifalacqua, M., Ghafoori, A., \& Jacobowitz, M. (2019). A hidden healthcare crisis: Youth homelessness. Nurse Leader, 17(3), 193-196.

UN General Assembly (1989). Convention on the Rights of the Child, United Nations, Treaty Series, vol. 1577, p. 3. Retrieved from https://www.refworld.org/docid/3ae6b38f0.html [accessed 1 March 2020].

\section{Notes}

${ }^{1}$ The image description is as follows. A hand-drawn heart in the middle of the page, with the word community written on the bottom left side of the heart. Behind the heart, a list of words is written - acceptance, love, together, caring, family, unity, harmony, friend, connect, neighbourhood, united and prevail. The poster has a picture of the sky and clouds in the background.

${ }^{2}$ The shelter, disabilities, and shelter + disabilities team included the OYAG members and the three MA CYC students. The social media team included three MA CYC students. The image description is as follows. There is a pie chart divided into four equal sections, with two arrows in the middle rotating in the shape of a circle. The top left pie, coloured dark yellow, states "shelter. Focus: connection, support, activities." The bottom left pie, coloured yellow, states "disabilities. Focus: recreational activities, support, connection." The top right pie, coloured yellow, states "shelter + disabilities. Focus: collaboration, relationship building, activities." The bottom right pie, coloured peach, states "General Facebook group. Focus: education, connection, youth-led initiatives. Instagram. Focus: sharing, advertising, inspire."

${ }^{3}$ From this point, when referring to "we" it includes both the CYC students and the OYAG members

${ }^{4}$ This poster is an example of written artwork posted to the Youth First Facebook group. The background colour of the poster is green with blurry white circles. The poster states "as a group we decided a theme of Community. I believe that as youth, we need to have a sense of community to support each other. As citizens we need to believe in each other and work collaboratively to build a better society. It is better to contribute to a good community and be a global citizen then to only care about ourselves. The written component of the artwork is as follows: As a 23-year-old male I have been diagnosed with Asperger's syndrome. This made my life tough because I had a lot of obstacles to overcome. During my early school years people bullied me and called me stupid and lazy. Obviously, this really made be upset because I felt like an outcast. I had very few friends growing up, although fortunately I did have a couple of close friends that had my back. 
They were there for me when I needed them most. I also have an older brother who is incredibly supportive and a good role model for me. I am also fortunate to have a loving family with supportive parents. Therefore, I do consider myself fairly lucky although my life really turned around when a teacher in elementary school believed in my potential and at that time hidden talents. My teacher guided me and gave me perspective about what was really important, and also gave me a sense of hope because he told me that I was very capable. He told me that I was smart and that every student should be treated with respect. He would encourage me to work hard and to never give up no matter what people said about me! At the end of my elementary school time, I was awarded the Principal Award for Leadership. This success encouraged me to fully participate in all school activities, pursuing my interests in sports and music. I was not successful all the time but at least I felt part of the community.

Through this experience I realized the importance of community for all of us and the importance of supporting others. Folks that were close to me and cared about me, help by giving me hope along with convincing other people to have faith in me as well. If we want people to be valued and to become valued in the eyes of others, then we must do things which strongly prompt others to perceive them in positively valued ways and they must be perceived by others as holding valued social roles. Everyone has a positive social role to contribute in the community and should be given the opportunity to enjoy the good things in life.

As a newly graduated student in the (DSW) Developmental Service Worker program at Centennial College, I want to help the intellectually disabled to have a supportive community where they can be active community members. I know from personal experience the feeling of being socially isolated and how the sense of belonging can boost a person's sense of well-being. This is what inspires me to use a community theme in the Call of Youth Advisory group to help create strong communities throughout the city of Toronto.

By supporting strong communities throughout the city of Toronto we can help build stronger citizens. By supporting stronger citizens, we can build a stronger society! Every citizen deserves to be perceived to have a positive social role within their community. If we can help citizens to be perceived positively by the rest of society then we can build a better world!" The bottom right corner states "J.W."

${ }^{5}$ The poster on the left promoted the Youth First art initiative, where different themes were cocreated by the OYAG members and the CYC students. The image description is as follows. There are two posters in this image. The left poster has three yellow stars on the top right corner, with a picture of a pride flag on the left and right side of the poster. The poster states "Youth First: Online Youth Advisory Group. Canada-wide themed art showcase. Call for submission. Art, photography, music, writing, video, TikTok. All forms are welcome! Our fourth weekly theme is strength. What gives you and your community strength during this time? Here's how to participate: create art exploring themes of strength. Submit your artwork with first name, age, and general location (city, town, etc.) to youthfirst.ryecyc@gmail.com or YouthFirst:OnlineYouthAdvisoryGroup and see your artwork on the Youth First platforms!" At the bottom of the page, the poster states "new themes each week! Community (June 15-21) - Hope (June 22-28) - Connection (June 29-July 5) - Strength (July 6-12) - Together While Apart (July 13-19)". The right poster includes a drawing of a guitar with a sign that says "live music" on the right side of the poster. There is a drawing of a microphone on the left side of the poster. The poster states "Youth First invites you to share, listen and join Open-Mic Hour. Share your talents and passion with others (singing, dancing, poetry, motivational talk, and more!) Wednesday July 
29th, 2020 6-7 PM. Zoom link will be sent to you directly! Comment or message us to register and receive more info!" On the bottom left of the poster, there is an Instagram icon. In the bottom centre of the poster, there is a drawing of a laptop. On the bottom right side there is a white thumbs up icon inside of a blue circle.

${ }^{5} \mathrm{We}$ share our gratitude to IKEA for their generous and timely response to our request for donations, Avenue 15 for informing the Youth First team of the high-needs items and accepting the donations, as well as Canada Post for providing discounted shipping for the items to be delivered to Calgary from Ontario. The image description is as follows. A picture of a brown box containing IKEA items, such as three black and white cell phone chargers on the left, two packs of rainbow coloured pencil crayons on the right, five packs of coloured papers of white, green, pink, red and yellow, with three black and grey containers of markers on the bottom left and right. The container has a white sticker containing the product information, such as the product name, which is Mala, as well as the barcode, illustrations of the markers, and a warning choking hazard symbol. 